\title{
DEVELOPMENTAL VARIATION OF CHIASMA FREQUENCY IN CHORTHIPPUS BRUNNEUS
}

\author{
IAN MAUDLIN* \\ Department of Genetics, University of Birmingham, Birmingham B15 2TT
}

Received 19.iv.72

\section{INTRODUCTION}

Developmental differences in chiasma formation may be regarded as environmentally produced variation since differences arise between genotypically identical cells in response to changes in what may loosely be described as the internal environment. Rees and Naylor (1960) demonstrated well-defined patterns of variation in chiasma frequency within anthers of rye. They attributed this variation to the system of distribution of nutrient or other substances to the anther during its development and also to competition between different regions of the anther. Henderson and Edwards (1968) have shown that chiasma frequency in mouse oocytes is affected by maternal age, the frequency being reduced as maternal age increased. This study is concerned with investigating two aspects of developmental variation in chiasma formation in male Chorthippus brunneus (Thunb.). Firstly, an attempt was made to relate developmental variation between specific cysts of the same " age " to the structure and differentiation of the testis. Secondly, a survey conducted over several weeks attempted to relate chiasma frequency variation to developmental age.

\section{Materials AND methods}

In the first experiment 10 male grasshoppers were taken at random from a natural population, their testes dissected under insect saline and fixed in $1: 3$ acetic alcohol. Squash preparations of single follicles were made such that three follicles were scored from each half testis, the chiasma frequency of 10 cells being scored for each follicle. Preparations of intact follicles showed only one scoreable cyst per follicle and follicle differences were therefore taken to represent differences between individual cysts.

In the second experiment male larvae were caught and kept in an incubator at $30^{\circ} \mathrm{C}$. for a minimum of 10 days before fixation. Sampling was carried out with the aid of a colour code to provide seven age-groups each of five insects ranging from last instar larvae to 5-week-old adults. Testes from each insect were bisected, fixed and squash preparations made from each half testis. Preparations were coded and randomised prior to scoring.

\section{RESULtS AND DISCUSSION}

An analysis of the results of experiment 1 (table l) shows that apart from differences between insects, significant differences in chiasma frequency

* Present address: London School of Hygiene and Tropical Medicine, Keppel Street, London WCLE 7HT. 
TABLE 1

Analysis of variance of total chiasma scores of single follicles from ten adult males

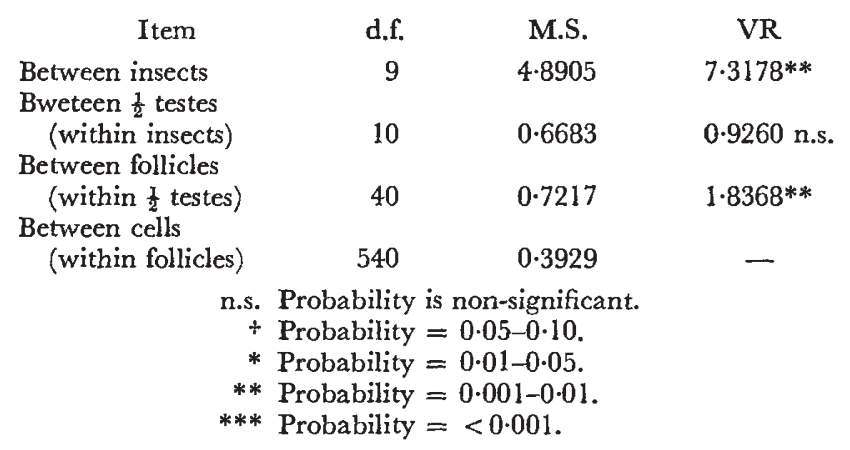

were also found within insects between different parts of the testis. Thus, chiasma frequencies of single follicles differ significantly when compared to variation between cells within follicles. This is a clear indication of " developmental" variation in chiasma frequency between follicles which can be loosely ascribed to micro-environmental differences affecting differentially the chiasma frequency in different parts of the testis. The homogeneity of the between-follicle variances of the 10 insects was examined by Bartlett's test using the variances of the follicle totals from within each testis. The result (corrected $\chi^{2}=18.8257 * *$ ) shows that the variances are significantly heterogeneous. Clearly the degree of between follicle variation found in this experiment varied considerably from insect to insect. This may be interpreted to mean that the degree of developmental or microenvironmental variation between follicles is not constant but varies depending on some other factor and it is tentatively proposed that the genotype may be involved. Rees and Thompson (1956) reached a similar conclusion from their studies on inbred lines of rye. They found that the degree of between cell/within anther variation in chiasma frequency was influenced by the genotype of the lines.

The second experiment was designed to investigate the influence of developmental age on chiasma frequency. An analysis of variance (table 2) revealed significant differences in chiasma frequency between age-groups even when compared with the quite considerable differences between insects within age-groups.

The change in chiasma frequency with age is shown in fig. 1. The regression items were tested using an analysis of variance, the results of which are shown in table 3 . Since the regression item is significant it may be concluded that as the age of the group of grasshoppers increases so the

TABLE 2

Analysis of variance of total chiasma scores of half testes for each of five insects in seven age-groups

$\begin{array}{lccc}\quad \text { Item } & \text { d.f. } & \text { M.S. } & \text { VR } \\ \begin{array}{l}\text { Between age-groups } \\ \text { Between insects }\end{array} & 6 & 32 \cdot 9300 & 2 \cdot 2522^{*} \\ \quad \text { (within age groups) } & 28 & 14 \cdot 6207 & 4 \cdot 2117 * * * \\ \begin{array}{l}\text { Between testes } \\ \quad \text { (within insects) }\end{array} & 35 & 3 \cdot 4714 & -\end{array}$




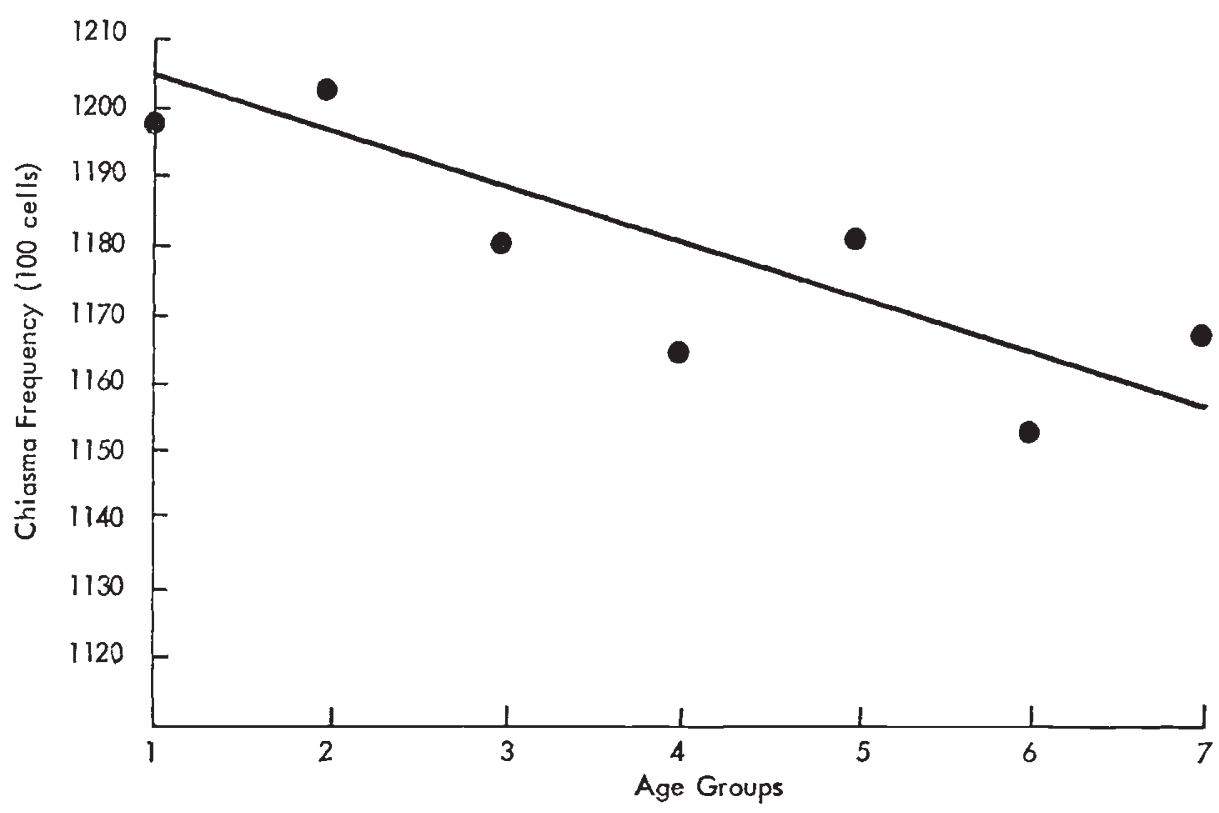

FIG. 1.-Total chiasma scores plotted against age group. Each point represents the total chiasma frequency for 20 cells from each of five insects.

chiasma frequency falls. The mean chiasma frequency of the youngest and oldest groups differed by 0.31 chiasma per cell. The biological and genetical significance of reducing chiasma frequency is unknown. This decline would have the effect of reducing the variability of the progeny of aged fathers. It may be that the reduction in chiasma formation is adaptive to secure greater or lesser variability in progeny appearing at various times in the next season. However, there is little or no evidence to suggest that laying date is correlated with hatching date (Moriarty, 1969). Hence, declining chiasma frequency may have no adaptive significance and may simply reflect the unavoidable developmental consequences of ageing.

TABLE 3

Analysis of variance of regression items for total chiasma frequencies of five insects from each of seven age-groups

$\begin{array}{lrrc}\quad \text { Item } & \text { d.f. } & \text { M.S. } & \text { VR } \\ \text { Regression } & 1 & 1170 \cdot 6785 & 7 \cdot 2701^{*} \\ \text { Remainder } & 5 & 161.0243 & 1.1013 \text { n.s. } \\ \text { Error } & 28 & 146.2070 & -\end{array}$

\section{Summary}

1. Mean chiasma frequencies were calculated separately for six single follicles for each of 10 insects sampled from a natural population. The between follicle variation in chiasma frequency is a clear indication of developmental, micro-environmental factors. However, the heterogeneity of the 10 between follicle variances suggests that the degree of between follicle variation depends on genotype. 
2. Significant differences in mean chiasma frequency were found among seven age-groups each consisting of five insects. As the age of the grasshoppers increases so the chiasma frequency systematically falls.

Acknoweledgment.-I am indebted to Dr Gareth Jones for his helpful advice and wish to acknowledge the receipt of an S.R.C. Advanced Course Studentship.

\section{REFERENCES}

HENDERSON, s. A., AND EDWARDS, R. G. 1968. Chiasma frequency and maternal age in mammals. . Nature, 218, 22-28.

MORIARTY, F. 1969. The laboratory breeding and embryonic development of Chorthippus brunneus Thunberg (Orthoptera: Acrididae). Proc. R. ent. Soc. Lond. $(A), 44,25-34$.

REES, H., AND NAYLOR, B. 1960. Developmental variation in chromosome behaviour. Heredity, 15, 17-27.

REES, H., AND thompson, J. B. 1956. Genotypic control of chromosome behaviour in rye. 3. Chiasma frequency in homozygotes and heterozygotes. Heredity, 10, 409-424.

\section{BOOKS RECEIVED}

THE GENETICS OF THE MIMETIC BUTTERFLY PAPILIO POLYTES L. C. A.Clarke and P. M. Sheppard. Published by Royal Society (in Phil. Trans.), 1972. Pp. 26. $£ 1.50$.

COLD SPRING HARBOR SYMPOSIA ON OUANTITATIVE BIOLOGY, VOI. XXXVI 1971STRUCTURE AND FUNCTION OF PROTEINS AT THE THREE-DIMENSIONAL LEVEL. Cold Spring Harbor Laboratory, 1972. Pp. 592. \$30.

THE ANALYSIS OF BIOLOGICAL POPULATIONS. Mark Williamson. Edward Arnold, 1972. Pp. 180. . 44.00.

CHARLES DARWIN: THE YEARS OF CONTROVERSY. Peter J. Vorzimmer. Univ. of London Press, 1972. Pp. 300 . $£ 4.40$.

THEORETICAL ASPECTS OF POPULATION GENETICS. Motoo Kimura and Tomoko Ohta. Princeton U.P., 1972. Pp. 219. \&6.00. 